UDC 551.4

\title{
FAR-EASTERN SPECIFICITY OF THE RELIEF FORMS' ASYMMETRY (BY THE EXAMPLE OF THE RUSSIAN FAR EAST)
}

\author{
Skrylnik Gennady Petrovich \\ Federal State Budgetary Institution of Science \\ Pacific Geographical Institute, FEB of RAS, Vladivostok \\ Centre of the landscape-ecological investigations, \\ leading research worker, geoecologist, cand. Sci. (Geography)
}

\begin{abstract}
Аннотация Цель и задачи - исследование пространственно-временной анизотропности геоморфологических процессов и асимметрии разнопорядковых форм рельефа (на примере российского Дальнего Востока).

Исследования выполнены с использованием «методов сквозного изучения комплексной географической оболочки» - сравнительно-географического, информационного, палеогеографического, а также некоторых других, разработанных автором.

Выполненные разработки, подчеркивающие новизну исследования, могут быть востребованы в практике выбора оптимальных вариантов природопользования, с учетом минимизации возможных геоэкологических рисков.
\end{abstract}

Abstract. The purpose and objectives are to study the spatial-temporal anisotropy of the geomorphological processes and asymmetry of multi-ordinal forms of relief (by the example of the Russian Far East).

The methods of "thorough study of the complex geographical envelope" (comparative-geographical, informational, paleogeographical) as well as other methods worked out by the author were used.

The carried-out developments emphasizing the novelty of the study can be demanded in the practice of choice of optimum alternatives of the nature management with respect of minimizing the possible geo-ecologic risks.

Ключевые слова: анизотропность; асимметрия; дисимметрия; склоновые процессы; российский Дальний Восток.

Key words: anisotropy; asymmetry; dissymmetry; slope processes; Russian Far East.

\section{Introduction}

In the differently expressed long-time manifestation of asymmetry, the spatial-temporal anisotropy of geomorphological processes and relief forms is fixed to the maximum extent. Herewith, the assembly of the absent symmetry elements in the system of which the asymmetry serves as the special case is thought of as the dissymmetry. It is telling that ".. a world consisting of the forms of the land surface gives every now and then the examples of symmetric and dissymmetric relations in their diverse combinations" [1, page 9]. On the Earth's surface, the asymmetrical forms of relief prevail. Therefore, the asymmetry is one of the common properties of relief reflecting not only current but also final total of developing the multi-ordinal and genetically heterogeneous forms. In addition, the asymmetry contains certain information on origin of forms.

A registry of symmetry and asymmetry as one of the links of the morphological analysis of relief results, as a result, in the significant historical and genetic conclusions [2].

Herewith, it is necessary to distinguish three types of asymmetry of: a) river banks; b) slopes of valleys and c) watersheds. All of them are closely interrelated. The asymmetry of the slopes of river valleys is the most commonly encountered. There are a variety of theories explaining its origin. They can be consolidated into several groups: hydrodynamic, planetary, climatic and structural-geologic.

Purpose and objectives are to study the spatial-temporal anisotropy of geological

processes and asymmetry of multi-ordinal forms of relief (by the example of the Russian Far East).

Data for study: the data of the multi-year geomorphologic and geo-ecologic studies of the author in Chukotka and Wrangel Island (1957-1959, 1971-1972); in the basin of Kolyma River and in Sea of Okhotsk region (1971-1972, 19741975); on lowlands (1974-1979), in the mountains, coastal areas and islands of the southern Far East (2007-2018) as well as accessible literature and archival sources were used.

Methods. The methods of "thorough study of the complex geographical envelope" (comparative-geographical, informational, paleogeographical) [3] as well as other methods worked out by the author [4] were used.

\section{Results and discussion}

It is conceivable that the development of a definite variant of asymmetry contains, for the most part, in the laws of nature.

From a global perspective, as the most striking instance of such predeterminacy of asymmetry (for example, accumulative-denudative formations), the development of opposite types of asymmetry of large river valleys in the 
northern and southern hemispheres caused by the differently-directed effect of the Earth rotation force and inclination of its axis to ecliptic plane (as reflected in the Baer-Babinet law) must be considered [5].

Regionally, the essential role of asymmetry of low-ordinal erosive forms caused by the anisotropy of geomorphological processes on the slopes of different expositions in the valleys of small rivers is identified (according to the data of numerous authors: A.A. Borzova, 1913; I.S. Shchukin, 1934; S.S. Voskresensky, 1947; E.A. Presnyakov, 1955; Yu.G. Simonov, 1959; G.M. Epstein, 1961; A.M. Korotky et al., 1977). Such asymmetry of the relief forms is caused by climate because it fixes the irregularity in the distribution of the daily, seasonal and annual quantities of heat and moisture. This is most unique to the meso-slopes where the above-noted irregularity regulates the processes of erosion and accumulation, first of all, in the low-order erosive forms. Such, locally developing processes cover huge territories of Siberia and Far East and, therefore, become the regional factor of the climo-morphogenesis [6].

The symmetry and asymmetry of multi-ordinal morphostructures reflecting the different extents of symmetry of the processes originated them are not less expressive $[2,7]$. It should be added that the anisotropy of the deep processes determining the nature and extent of the asymmetry of morphostructures and, whereby, differentiated the conditions of climo-morphogenesis, continues so far to have a meaningful effect on the completeness of spectrum and intensity of the proceeding accumulation-denudation processes. Other things being equal, the primarily symmetric forms are more stable in time as compared with the asymmetric ones. Within the limits of the primarily asymmetric morphostructures (from the moment of their distinct morphologic expression), the anisotropy of geomorphological processes the value of which is proportional to the value of the morphostructures' asymmetry is sharply manifested. For example, different intensity of the erosion-denudation processes on the western gentle and eastern steep macroslopes of the Sikhote-Alin appears as the consequence of significant role of asymmetry of this morphostructure.

Such effects of the sharp asymmetry of the large-order categories of relief on the process of climo-morphogenesis are also characteristic of the extensive areas of the Korean Peninsula and the north-western Sea of Okhotsk region.

\section{Analysis of the asymmetry of the river valleys' slopes and interfluve areas}

The maximum demonstration of the anisotropy of natural processes and caused by it features of the relief structure were fixed in the asymmetry of the slopes of river valleys and interfluve areas. The formation of the type and large scale of the valley asymmetry in the multi-ordinal river systems and at different stages of its development is predetermined by the action of different factors.

In the paper, the morphogenetic manifestations of global factors in the emergence of symmetry and asymmetry of the slopes of valleys and interfluves areas are not considered. We illustrate only thematic regional and local features related mainly to the activity of only fluvial agents and slope processes. The latter are controlled by the spatial-temporal contrasts of heat and moisture which are most dynamic within the temperate zone of the Far East (Primorye and Khabarovsk Krai) which is here due to maximum extent of monsoon conditions of climate [7].

Role of fluvial agents. A development of the slope asymmetry at the level of the current riverbed and second bottom is determined by the laws of the channel flow migration within the valley bottom. This influence is fixed especially clearly in such valleys where the width of meander belt is close to the bottom width. The alternate undercutting of the slopes with different expositions at the sections of approaching the river bends tops (due to their transverse displacement) to the original sides or slopes of terraces determines the interchange of the steep and gentle slopes along the strike of the valley. In addition, due to the deep stream displacement in regard to axis of channel, the river bends are exposed to longitudinal motion down the river. Such displacement of meanders in the process of prolonged effect on the sides of valleys results, after all, in the formation of the symmetric river valley with progressively convex slopes. In such a way, the rates of transforming the lower sections of the slopes depend on the intensity of transversal displacement of river bends and speed of longitudinal migration of the meander belt fluctuating greatly due to frequent (especially, in summer) multiple-elevation and prolonged rainfall floods.

In valleys of the mountain rivers, the displacement of the dynamic axis of the flow obeys the law of "reflection of elastic balls" which determines the formation of sharp bends of the riverbed (according to observations of M.A. Velikanov, 1964), for example, in the mountains of the Far East). The intensity of transverse deformations of the riverbed is also enhanced by its not large stability at the sections of active accumulation. As the transverse slopes of the valley bottom are significant, the mountain stream can, during the relatively prolonged period, exert an effect on the same segments of slopes. In this case, the effect of high-velocity flows on the original sides of the river valley exceeds manifold such indices for the lowland rivers and the transverse migration of the riverbed becomes the predominant process in developing the sides of river valley. If however this process lines up additionally with the intense deep erosion under conditions of the monsoon humification of territory (in particular, in Primorye), a valley with entrenched meanders and well-defined and long-lived balanced system of slopes determining the alternate asymmetry of slopes.

The above-described character of the asymmetry emerges also in the mainstream valleys due to deflection action of the equal in value left and right inflowing streams - effect of "play of inflowing streams" (according to the data by N.I. Makkaveev, 1971). Alternate effect of these inflowing streams on the processes in the main channel results in formation of the "slightly winding" valley with well-pronounced alternating-sign asymmetry of slopes.

Materials of our studies show that the climatic asymmetry is manifested with maximum sharpness in the river valleys with moderate value of the erosion cutting and basin exposition close to neutral. With increase of cutting and enhancement 
of fluvial processes, the identification of valleys with well-pronounced climatic asymmetry is difficult. This is one of the causes of the striking anisotropy of the slope processes caused by climatic conditions only in the belt of the torsodenudation and small- and low-mountain relief [2].

In addition to the above-said, we note that all the cases of developing the alternate asymmetry of the river valley slopes considered by us (based on the data of studies of many years in the southern and northern Far East) are only characteristic of the catchment basins with areal (basin) and hypsometric symmetry.

Role of slope processes.. The asymmetry of slopes of river valleys and interstream areas caused by climatic conditions is connected first of all with the anisotropy of the slope processes $[2,6]$. The regional studies in the Middle Siberia and Far East [7, 8] have revealed the wide-spread occurrence of the "climatic" asymmetry of slopes both in area of permafrost formation and beyond its borders (according to the data by E.A. Presnyakov, 1955; Yu.G. Simonov, 1959; G.M. Epshtein, 1961; S.S. Voskresensky, 1962; author (1968); I.I. Krylov, 1976; A.M. Korotky et al., 1976; and others).

In the Far East, we have established the specific features of developing the asymmetry of slopes in small rivers (up to 3-4 orders). Here, 2 types of asymmetry (southern warm and northern cold) are identified. These types are characteristic only of the latitude-oriented valleys and caused by incoming of solar radiation. As a result, they wholly correspond regionally in nature to continental and oceanic (in both cases, with the southern and northern components) landscapetransforming effects.

Within the framework of the southern type (continental space), the slopes of the southern exposition (SE) heat up fairly well, moisten insufficiently and are exposed to temperature erosion and slow-acting displacement due to deserption and, for that reason, they are always steep while the slopes of the northern exposition (NE) are shadowed, frequently water-logged, exposed to the frost weathering and displacement due to slow solifluction and, for that reason, they are more gentle.

Within the scope of the northern type (continental territories), the SE slopes heat up to some extent, thaw out seasonally and, as a result, they are excessively moistened, exposed to displacement due to slow-acting solifluction and, for that reason, they flatten out while the NE slopes are shadowed, do not thaw out, are practically not exposed to displacement and preserve their steepness.

Facing away from the intracontinental territories to the coastal ones, concurrently with the enforcement of the climate oceanicity and environment-forming role of hypsometry causing the disturbance of latitudinal zonality, the progressive appearance of longitudinal modifications complicating the overall pattern of asymmetry of the small river valleys is noted.

The longitudinal modifications are divided as follows:

a) continental (within the scope of the southern type of asymmetry, the WE slopes are drier and steeper while the EE slopes are wetter and more gentle; within the framework of the northern type, the EE slopes are relatively shadowed, frost bound, less wetted and steeper while the WE slopes, when thawing the frost-bound horizon, are wetted and more gentle).

b) oceanic (the WE slopes are drier and steeper while the EE slopes are waterlogged and gentle). The existence of this modification is caused by not radiation but direction of inflowing precipitation (as a result, the well moistened slopes develop more quickly due to the monsoon solifluction and become more gentle).

A borderline between these two modifications passes along the Pekulney ridge (Chukotka) and Penzhensky ridge (Kamchatka) in the north and along the Sikhote-Alin ridge (Primorye) in the south [8].

The latitudinal zones of asymmetry are separated by the "symmetry belt" (mainly, from 50 to $55^{\circ} \mathrm{N}$ ) experiencing together with the southern type of asymmetry the greatest changes over the course of the Quaternary period). Very likely, these bands of asymmetry absence are fairly mobile in time and can show the possible multi-period reconstructions in tendencies of development of 2 types of asymmetry while the time of their existence is the time index of the dynamic equilibrium of the physic-geographical situations on all slopes.

The illustration of the spatial development of the valley slopes of small rivers in the southern Russian Far East is presented below (see Table).

Table.

Climatic asymmetry of the valleys slopes of small rivers (expositional occurrence of the steep and gentle slopes in different types of asymmetry and modifications)

\begin{tabular}{|c|c|c|c|c|}
\hline \multirow{2}{*}{ Type of asymmetry } & \multicolumn{3}{|c|}{ Modifications of asymmetry } \\
\cline { 2 - 5 } & \multicolumn{2}{|c|}{ Continental } & \multicolumn{2}{c|}{ Oceanic } \\
\cline { 2 - 5 } & Steep slopes & Gentle slopes & Steep slopes & Gentle slopes \\
\hline Northern (NE slopes are steep; SE slopes are gentle) & EE & WE & WE & EE \\
\hline Southern NE slopes are gentle; SE slopes are steep) & WE & EE & WE & EE \\
\hline
\end{tabular}

In such a way, these types and modifications of asymmetry of the river valley slopes are identified in accordance with changes in tendencies and intensity of the continentality proper (when changing the southern effects with northern ones from the south to the north) and complex dynamic relations of continentality and oceanicity in the direction from north to south. In such a way, the climo-morphogenesis changes in the direction from south to north and also from intracontinental areas to the coastal ones [6,7], i.e. in the direction of continentality increase in the region [9]. At the same time, the close 
relationship of the anisotropy of slope processes with the spatial-temporal changes in climate for an anthropogenic period (according to the data by V.V. Nikolskaya and author, 1976; A.M. Korotky and others, 1977).

The above-described regional and local differences in asymmetry are characteristic of all continental margins of the Northern hemisphere (to a greater degree of the eastern than western) but their variety in forming the complexly interwoven different types and modifications of asymmetry the small river valley slopes is most unique to the south of the Russian Far East.

The suggested [10] substitution (in view of comments to earlier published paper [2]) of the names of both author's modifications of asymmetry of the meridional valleys (continental and oceanic) for only oceanic one (Atlantic and Pacific respectively) should be rejected. One can identify the oceanic modification with the Pacific one as the possible refinement. It is misguided to consider the proposed "Atlantic" modification as the oceanic one. By its effect for the Far East, it is yet still continental. This is explained by the fact that the primarily Atlantic air masses are greatly transformed after crossing of Europe and turned into the continental ones. For this reason, their ultimate impact on the slopes is "continental" rather than oceanic.

Against the background of the moving denudation bases which is quite common for the southern Far East [11], the fluctuations in the asymmetry contours of the small river valley slopes change essentially. Such cases are characterized by the extreme specificity but their consideration is a theme of the separate article and does not discuss here.

Based on new data of our ground and aerovisual observations and analysis of aerial photographs and lathe-scale chars with the involvement of already published materials, the general and the particular regularities of developing the asymmetry of small river valleys for particular natural-climatic areas (Wrangel Island, Chukotka, Upper Kolyma River region, Sea of Okhotsk megacoast, northern slope of the Stanovoi Range and Verkhnetimtonskay cavity as well as YamAlin and Dusse-Alin, Sikhote-Alin Range) [12] were revealed. It is natural that they are not considered here.

Role of hypsometry. In the highlands of the Far East, the numerous situations are observed when, in case of wellpronounced basin asymmetry, the valley asymmetry opposite in sign develops. This is very good traced, for example, in the process of the transverse profiling operations of interfluves and valleys of Kievka River (at a section of Staraya Kamenka - Novitskoye settlements) and Partizanskaya River (at a section of Sergeevka - Novitskoye settlements). Difference in signs of the basin and valley asymmetry here is explained, in our opinion, by their different origin: first of them is caused by the hypsometric contrasts of the catchment areas while the second one is connected with climatic differentiation of the valley-forming processes under these conditions.

The hypsometric asymmetry in the above cases is a result of the intense uplift of the Sergeevsky anticlinorium and Sestrinsky granite massif (South Primorye) within which there are the lesser parts of catchment areas (right for Kievka River and left for Partizanskaya River). The water courses originating here (with maximum in region marks in the Sestrinsky, Alekseevsky and Benevsky ridges) have the lesser length than the opposite tributaries of the main rivers. At the same time, the greater average slope providing for them the larger erosive capacity is naturally characteristic of them. As a result of this, the water courses of the "short" slopes have carried out to the main valleys the large volumes of the coarse-grained materials shifting that way over the considerable distance the Kievka riverbed to the left and Partizanskaya one to the right. In some segments, this process exists also currently but only during extreme water floods.

An analysis of the areal extent of the multiple-aged Pliocene-Quaternary terraces in the basins of Kievka and Partizanskaya Rivers leads to conclusion that the most active formation of symmetry of slopes of river valleys coincides here with the cold epochs of the Middle and Late Pleistocene. A key role in the "rolling" of the main rivers (Partizanskaya to the right and Kievka to the left) was played by the debris cones of their tributaries. This allows us to consider the climatic factor (as compared with tectonic one) as no less important reason of the directional "rolling" of the riverbeds [2, 12].

As a result, the asymmetry of the valleys of main rivers is a result of the complex interaction of the tectonic and climatic factors of relief forming. Herewith, the dynamic state of interacting factors is of fundamental importance. In the case considered by us, the morphogenetic effect of such interaction is sharply differentiated in time: a) decrease in the "rolling" speed of rivers, extent of the valley asymmetry and value of difference between the valley and basin asymmetry during "warm" epochs; and b) sharp rise in all these processes and phenomena which is causally related first of all to the enhancement of regional and local contrasts of heat and moisture intensified targetedly by the continentality increase in the region during "cold" epochs.

\section{Analysis of the asymmetry of the coastal relief forms}

The anisotropy in the manifestation of coastal processes and related to it asymmetry of the coastal forms of abrasion and wave accumulation are a result of the complex interaction of many natural factors: a) wind activity and related to it heaving of the sea; b) orientation and configuration of the coastland and roughness of shallow-water relief; c) fluctuating seasonal ice coverage of the sea and so on $[2,7,12]$. The anisotropy of the coastal processes against this background reflects the historical strains of the forming the coasts as a result of: a) heterogeneity of tectonic development of coastal sections of land and shelf; $b$ ) definite trend in change of the coastal forms caused by the long-period fluctuations of climate and eustatic fluctuations of the sea level.

All of these factors determining the essence of the hydrodynamic processes in the coastal band of land and in the shallow marine shelf are also related to the sediment balance in the coastal zone. So, depending on the quantity of detrital material entering to the wave-built belt as well as on rate of its redistribution along the littoral and coast, the development of relief in the coastal zone takes place in accordance with abrasion or accumulation. By the example of the northwestern 
coast of the Sea of Japan, we will demonstrate to what extent the anisotropy of coastal processes determines the asymmetry of the valley and coastal forms of relief.

Amongst the variety of asymmetry manifestations of abrasive and accumulative formations inshore and in the estuary parts of valleys emerging at different stages of developing the coastal territory and water area, one can identify and characterize six basic types of asymmetry (see Figs. I-VI).

The specific nature of developing the asymmetry of the coastal relief forms for basic types is revealed as follows [2, 12].

I. In case of regular change in the resultant force of seaways, the ingression bay emerges over the period of the Middle-Late Holocene. It is characterized by the roughly same in steepness progressively-convex slopes and symmetrically located (with respect to the axial part of valley running into the bay) entry capes and proximal ends of the ancient and current-day accumulative forms (see Fig.). Periodic deviation of the river mouth by the beach drifts is of no great consequence in developing the asymmetry of the coastal relief forms. Such structure is more often characteristic of the mouths of large rivers (for example, Kievka, Chyornaya, Zerkalnaya) carrying out the sufficient amount of material redistributed later on by the beach drifts periodically changing their direction to the wave-built band.

Fig. Character of asymmetry of the coastal-maritime forms of relief and estuary segments of river valleys.

Legend: 1 - second terrace above the flood-plain; 2 - first terrace above the flood-plain; 3 - high flood plain and current-day riverbed; 4 - ancient marine terrace; 5 - current-day beaches; 6 - lagoonal terrace; 7 - progressively concave (a) and progressively convex slopes (b); 8 - abrasion scarps (abandoned (a) and active (b)); 9 - axes of bays and valleys; 10 - current deposit drifts; 11 - ancient deposit drifts; 12 - geomorphologic profiles; 13 - contours of abrasive platform; $\mathrm{K}_{\mathrm{as}}$ - coefficients of asymmetry (determined using the methodology of L.I. Ferdman, 1970) as the measure of spatial deviation of valley axis from the riverbed (to the right with left-hand sign and to the left with right-hand sign).

Compiled by A.M. Korotky and G.P. Skrylnik

II. The relief of estuary part of valley and adjacent to it seashore is formed mainly under the action of beach drifts the prevailing direction of which has preserved long time, at least, for nigh on 6 thousand years. In this case, the asymmetric distribution of facies is observed within the plain of accumulation. In addition, the accumulation of beach deposits takes place mainly along the lee side of the bight while the lagoonal and alluvial-lagoonal deposits are accumulated along the opposite side. The estuary of the river within such asymmetric bight is commonly pressed to the windward entry cape. Oftentimes, the river valley in the segment of the ingression lagoon has the asymmetric structure which is fixed by relatively gentle leeward slope and well-defined abrasion scarp in the windward slope (see Fig. II). This is most unique to segments of the ingression-embayed type of coasts (for example, in the estuaries of the Milogradovka, Margaritovka and other rivers).

III. In situations where, in the Late Holocene, the rapid change in direction of the beach drifts has taken place in the segment of the coast, the spatial asymmetry of multi-aged accumulative and abrasive forms of relief is observed in the estuary parts of rivers (see Fig. III). Such temporal anisotropy of the coastal processes can be related only to change in wind conditions. More often, the asymmetry emerges in the valleys where the ancient accumulative form was "formed" at the expense of abrasion products while the younger one at the expense of income of the alluvial material to the wavebuilt band (particularly, in the mouths of Maksimovka and Kema Rivers).

During floods, the river destroys usually in a number of locations the young accumulative form and after their termination when the flow force becomes weaker and deposits drift restores, the generated passages are filled with deposits.

IV. Sometimes, the asymmetry at foot of river valley is determined by the distinctive features of processes and does not depend on heaving of the sea. Here, in many valleys, the asymmetry of the estuary part is related to developing the meander belt. So, if the bend top approaches the right side in the overlaying section of valley, then, directly in the river mouth, the left-hand asymmetry will be observed and vice versa. This can be observed in the mouths of Peya, Svetlaya, Kuznetsova, Amgu and other rivers. In general, such structure is usually observed for such rivers where the lagoon situated near the mouth of a river is quickly formed by the alluvial material (see Fig. IV).

V. In the mouths of low-order water courses with well-defined complex of local terraces, the asymmetry of valleys and accumulative coastal-marine forms is of different nature. So, the asymmetry of river valley is usually related to the long and targeted displacement of the riverbed. In this case, on one side of such valley, the full range of the Quaternary terraces is observed while its other side represents the progressively-convex slope (see Fig. V). Such long-term targeted displacement of the riverbed at some sections is clearly related to the climate-responsive anisotropy of the slope processes. For example, the low-order valleys at the section of the Sea of Japan megacoast, from the mouth of Milogradovka river to the mouth of Margaritovka river have the terraced NE slopes and steep SE slopes. At other sections, the valley asymmetry is related to the basin or hypsometric one caused by the features of the geological structure of river basins.

VI. Of the majority of the estuary parts of the low-order water courses where the aforesaid role of the geological factor is significative, the abrasion scarp with the narrow attached beach is typical. Here, the wave climate determines the configuration and degree of asymmetry of abraded bights. In case of the durably targeted effect of the sea, the asymmetrically-jagged contour of coast line with en echelon location of entry capes appears (see Fig. VI). Note 
additionally that the contour of bights and river valleys at the sections of ingression-embayed coast disagree usually and character of asymmetry of the embayed and valley forms is different.

Therefore, in the relief of the coastal zone of the north-western mega-coast of the Sea of Japan, the various manifestations of anisotropy of the slope, fluvial and coastal processes the complex functioning of which was morphologically expressed in formation of a wide range of asymmetric valleys and coastal-maritime accumulative and abrasive forms of relief were fixed.

\section{Conclusion}

The richest and most variable spectrum of the spatial-temporal manifestations of asymmetry of multiple-ordinal forms of relief is characteristic of the Russian Far East (especially, its southern part). This stands in one-to-one correspondence with the maximally complex and different-scale interweaving here of continental and oceanic landscape-forming and, in part, relief-forming effects.

The climatic asymmetry is most clearly manifested in the valleys of small rivers (up to 3-4 order) with tempered value of the erosion cutting. The peculiar features of developing the asymmetry of the small river valley slopes were established. Here, there are 2 variants of asymmetry: northern (the slopes of the northern exposition are steeper while southern ones are gentle) and southern (slopes of opposite steepness). The latitudinal zones of asymmetry are separated by the "symmetry belt" (mainly, from 50 to $55^{\circ} \mathrm{N}$ ) while, in the direction from south to north, they are complicated by 2 modifications: continental (within the limits of the southern type of asymmetry, the WE slopes are drier and steeper and EE slopes are wetter and more gentle) and oceanic (WE slopes are drier and steeper while EE slopes are waterlogged and gentle).

An analysis of the presented materials shows that the continental relief-forming effect bears on the larger part of the Russian Far East and should increase even more in the future.

The carried out developments emphasizing the novelty of the study can be much-needed in the practice of choice of optimum alternatives of nature management with due account of minimizing the possible geoecological risks.

Acknowledgements. The work was carried out according to the thematic plan of the research and development of PGI, FEB of RAS, in line with state assignment of the RF Ministry of Education and Science for 2019-2020 "Natural and anthropogenic factors in evolution, dynamics and stability of multi-rank geosystems and their components in the landocean transition zone"; registration number of theme: AAAA-A19-11930790003-1.

\section{References}

1. Florensov N.A. Sketches of the structural geomorphology. Moscow: Nauka, 1978. 93 p.

2. Korotky A.M., Skrylnik G.P. Anisotropy of the geomorphological processes and asymmetry of multi-ordinal form of relief (by the example of the Far East) // Studies of global factors of the Far East climo-morphogenesis. Editors-inchief: Nikolskaya V.V., Skrylnik G.P. Vladivostok: PGI, FESC of the USSR Academy of Sciences, 1979. P. 118-142.

3. Markov K.K., Dobrodeev O.P., Simonov Yu.G., Suyetova I.A. Introduction to the physical geography. Moscow: Vysshaya shkola, 1973. 183 p.

4. Skrylnik G.P. Methodological approaches to determination of the stability of geosystems // Intern. Conf. "Interaction of the society and environment under conditions of global and regional changes (Moscow-Barnaul, July 1829, 2003)". Barnaul: IGU, NCGR, RGS, IG of RAS, MSU, IWEP of SB RAS, AltaySU, 2003. P. 298-299.

5. Kalesnik S.V. Foundations of general earth science. Moscow-Leningrad: State Publishing House of Educational and Pedagogical Literature, 1947. 484 p.

6. Skrylnik G.P. Zonal features of the asymmetry of river valleys of the Russian Far East // Hydrology and geomorphology of the river systems (Proceedings of the scientific conference. Editors: B.P. Agafonov, Dr. Sci. in Geography, L.M. Korytny, Dr. Sci. in Geography, G.F. Ufimtsev, Dr. Sci in Geol. and Miner.). Irkutsk: RAS, IG of SB RAS, IEC of SB RAS, GC RAS, ESS RGS, 1997. P. 234-235.

7. Geosystems of the Far East of Russia at the turn of the XX-XXI centuries: in 3 volumes. // coll. of authors; endorsed by acad. P.Ya. Baklanov, Vol. I/ Natural geosystems and their components // coll. of authors; editor-in-chief S.S. Ganzei. Vladivostok: Dalnauka, 2008. 428 p.

8. Korotky A.M. Reformation of the river network in Primorye: causes, mechanisms and influence on the geomorphological processes // Geomorphology. 2010. No. 2. P. 78-91.

9. Nikolskaya V.V. About the natural tendencies of developing the physico-geographical provinces of the southern Far East. Novosibirsk: Nauka, 1974. 127 p.

10. Kurzhanova A.A. Climatic asymmetry of the river valley slopes // Successes of the Modern Natural Sciences. 2018. No. 5. P. 169-175.

11. Makhinov A.N. Formation of slopes with moving denudation bases. Vladivostok: FESC of the USSR Academy of Sciences, 1985. $124 \mathrm{p}$.

12. Skrylnik G.P. Anisotropy and asymmetry of landforms (on the example of the Russian Far East) // Scientific research of the SCO countries: synergy and integration in Russia. Materials of the International Conference "Scientific research of the SCO countries: synergy and integration" Part 2: Participants' reports in English. December 11, 2019. Beijing, PRC. Beijing: 2019. P. 159-181. DOI 10.34660/INF.2019.22.43640. 